dẫn lưu hồi tràng là những yếu tố liên quan đến hội chứng LARS nặng sau phẫu thuật [7].

Trong nghiên cứu, phân tích các yếu tố liên quan bằng phương pháp Fisher's test cho thây; tại thời điểm 12 tháng sau phẫu thuật, các yếu tố điều trị hóa xạ trước mổ, vị trí u, vị trí miệng nối (trên đường lược, tại đường lược, dưới đường lược) và phương pháp thực hiện miệng nối có liên quan đến hội chứng LARS nặng sau mổ với $\mathrm{p}<0,05$ (bảng 3). Các nghiên cứu cho thấy rằng: đối với những tổn thương ung thư trực tràng thấp đồng nghĩa với thực hiện miệng nối thấp thì phẫu thuật là tăng nguy cơ tổn thương thần kinh tự động và cơ thắt hậu môn. Ngoài ra thể tích chứa phân của trực tràng mới giảm dẫn đến tăng nhu động ruột và đại tiện gấp[3], [2]. Đặc biệt những tổn thương ung thư trực tràng thấp $(<5 \mathrm{~cm})$ phần lớn bệnh nhân được thực hiện cắt trực tràng gian cớ thắt (có thể cắt bán phần, gần hoàn toàn và hoàn toàn cơ thắt trong) với miệng nối đại tràng ống hậu môn điều này có ảnh hưởng nhiều đến chức năng đai tiện của bệnh nhân sau phẫu thuật. Do vậy phẩu thuật viên cần tôn trọng cấu trúc giải phẫu, tránh tổn thương thần kinh tự động và bảo tồn tối đa cơ thắt hậu môn.

Nghiên cứu của chúng tối có một số hạn chế: việc đánh giá chức năng đại tiện sau phẫu thuật chỉ dựa vào các thang điểm đánh giá mà chưa có đánh giá bằng phương tiện đo áp lực hậu môn trực tràng. Ngoài ra, cần nghiên cứu trên số liệu bểnh nhân lớn hơn và thời gian theo dõi xa hớn để có đánh giá toàn diện hơn.

\section{KẾT LUẦN}

Rối loạn chức năng đại tiện của bệnh nhân ung thư trực tràng được phẫu thuật cắt trước thấp là vấn đề thường gặp và kéo dài sau phẫu thuật, chức năng đại tiện sẽ được phục hồi dần theo thời gian. Do đó theo dõi, hỗ trợ, tư vấn và điều trị của bác sĩ có ý nghĩa trong việc cải thiện chất lượng sống tốt hơn cho người bệnh.

\section{TÀI LIÊU THAM KHẢO}

1. Beppu N., et al., "Long-Term Functional Outcomes of Total Mesorectal Excision Following Chemoradiotherapy for Lower Rectal Cancer: Stapled Anastomosis versus Intersphincteric Resection", Dig Surg. 2016. 33, pp. 33-42.

2. Chen T.Y.T., Emmertsen K.J., Laurberg S., "What Are the Best Questionnaires To Capture Anorectal Function After Surgery in Rectal Cancer?", Curr Colorectal Cancer Rep. 2015. 11, pp. 37-43.

3. Dulskas A., et al., "Long-term bowel dysfunction following low anterior resection", Sci Rep. 2020. 10: 11882.

4. Ekkarat $\mathbf{P}_{\text {., }}$ et al., "Factors determining low anterior resection syndrome after rectal cance resection: A study in Thai patients", Asian J Surg. 2016. 39, pp. 225-231.

5. Emmertsen K.J., Laurberg S., "Low anterior resection syndrome score: development and validation of a symptom-based scoring system for bowel dysfunction after low anterior resection for rectal cancer", Ann Surg. 2012. 255, pp. 922-928.

6. Liu F., et al., "Risk factor analysis of low anterior resection syndrome after anal sphincter preserving surgery for rectal carcinoma", Chin J Gastrointest Surg. 2017. 20, pp. 289-294.

7. Miacci F.L.C., Guetter C.R., et al, "Predictive factors of low anterior resection syndrome following anterior resection of the rectum", Rev Col Bras Cir. 2020. 46:e20192361.

8. T.Y.T. Chen, L.M. Wiltink, "Bowel function 14 years after preoperative short-course radiotherapy and total mesorectal excision for rectal cancer: report of a multicenter randomized trial", Clin Colorectal Cancer. 2015. 14, pp. 106-114.

\title{
NGHIÊN CỨU CHỨC NĂNG THẤT PHẢI TRÊN SIÊU ÂM TIM Ở BỆNH NHÂN HẸP VAN ĐộNG MACH CHỦ KHÍT
}

\author{
Đỗ Mạnh Hùng ${ }^{1}$, Nguyễn Thị Hải Yến ${ }^{2}$, Nguyễn Thị Bạch Yến ${ }^{2}$
}

\section{TÓM TẮT}

Mục tiêu: Tìm hiểu tỷ lệ suy CN thất phải và mối liên quan giữa chức năng thất phải với một số thông

\footnotetext{
${ }^{1}$ Bệnh viện Bãi Cháy

${ }^{2}$ Bệnh viện Bach Mai

Chị trách nhiệm chính: Đỗ Manh Hùng

Email: manhhung180689@gmail.com

Ngày nhận bài: 13.9.2021

Ngày phản biên khoa họ: 29.10.2021

Ngày duyệt bài: 15.11.2021
}

số đánh giá mức độ hẹp van động mạch chủ và chức năng thất trái trên siêu âm tim ở nhóm bệnh nhân hẹp van động mạch chủ khít. Đối tượng: $B N$ hẹp van ĐMC khít (theo tiêu chuẩn của hôi siêu âm tim hoa kì: vận tốc tối đa qua van $>4 \mathrm{~m} / \mathrm{s}$, diện tích mở van động mach chủ $<1 \mathrm{~cm} 2$, chênh áp trung bình qua van $>40$ $\mathrm{mmHg}$ ) đến khám và điều trị tại Viện tim mạch từ tháng 8/2020-8/2021.Phương pháp nghiên cứu: mô tả cắt ngang chùm ca bệnh. Chọn mẩu thuận tiện. Siêu âm tim đánh giá $\mathrm{CN}$ thất phải (TAPSE, FAC, 'S', E/e' thành bên van ba lá, chỉ số Tei mô thất phải, ĐK thất phải). Kết quả: $47 \mathrm{BN}$ hẹp chủ khít đã được nghiên cứu siêu âm tim. Tỷ lệ suy chức năng thất phải 
toàn bộ (chỉ số Tei mô >0,54) là $68,1 \%$, suy chức năng tẩm thu $\left(\mathrm{S}^{\prime}<9,5 \mathrm{~cm} / \mathrm{s}\right)$ là $29,8 \%$, ( $\mathrm{FAC}<35 \%$ ) là $4,3 \%$. Chỉ số TAPSE có tương quan vừa với vận tốc tối đa qua van động mạch chủ $(r=0,389, p<0,01)$. FAC, Tei mô thất phải, vận tốc sóng $S^{\prime}$ đều có tương quan với chỉ số diện tích van động mạch $(r=0,361$; $0,297 ; 0,302 \mathrm{p}<0,05)$. Đường kính thẩt phải theo trục dọc (RVD3) có tương quan vừa với vân tốc tối đa qua van động mạch chủ $(r=0,38 p<0,01)$ và diện tích van động mạch chủ $(r=0,313 \mathrm{p}<0,05)$, chênh áp tối đa qua van $(r=0,411 p<0,01)$, chênh áp trung bình qua van $(r=0,412 p<0,01)$. Các chỉ số TAPSE, FAC, $S^{\prime}$, Tei mô thất phải đều có tương quan khá chặt chế với phân suất tống máu EF của thất trái với hệ số tương quan lần lượt là $(\mathrm{r}=0,512 ; 0,658 ;-0,372 ; 0,409 ; \mathrm{p}<$ 0,01). Kết luận: Suy chức năng thất phải khá thường gặp ở BN hẹp chủ khít. Chức năng thất phải có tương quan với vận tốc tối đa qua van động mạch chủ (TAPSE), với chỉ số diện tích van đông mạch chủ (FAC, $\mathrm{S}^{\prime}$, Tei mô) và chức nắng tâm thu thất trái .

Tư khóa: hẹp van động mạch chủ, siêu âm tim, chức năng thất phải

\section{SUMMARY \\ STUDY RIGHT VENTRICULAR FUNCTION IN PATIENTS WITH AORTIC VALVE SEVERE STENOSIS}

Aim: Study the rate of right ventricular dysfunction and the correlate between right ventricular function and some parameters assessing the stage of aortic valve stenosis and left ventricular function on echocardiography in patients with severe aortic valve stenosis. Subjects: Patient with aortic valve severe stenosis (According to the standards of the American Society of Echocardiography: peak velocity transaortic valve $>4 \mathrm{~m} / \mathrm{s}, A V A<1 \mathrm{~cm} 2$, mean aortic pressure gardient $>40 \mathrm{mmHg}$ ) came and treated at Tim Mach Quoc Gia hospital august 2020 to august 2021. Method: Prospective study, cross-sectional, choose convenient sample. Assessment right venticular function (TAPSE, FAC, $S^{\prime}, E / e^{\prime}$ lateral tricupid valve, RIMP, diameters of right venticular). Result: Forty-seven patients were studied by echocardiography. Incedence right ventricular global dysfunction assessment by Tei $(>0,54)$ is $68,1 \%$, right ventricular systolic dysfunction $\left(S^{\prime}<9,5 \mathrm{~cm} / \mathrm{s}\right)$ is $29,8 \%$, (FAC $<35 \%$ ) is 4,3\%. Right ventricular function measured by TAPSE was moderately correlated with maximal velocity through the aortic valve $(r=0.389, P$ $<0,01)$. FAC, Tei measured by tissue doppler, $S^{\prime}$ velocity were all correlate with index aortic valve area with correlation coefficient $(r=0,361 ;-0,297 ; 0,302$ $\mathrm{p}<0,05)$ respectively. The longitudinal right ventricular diameter was moderately correlated with the maximal velocity across the aortic valve $(r=0.38 p<0.01)$ and the aortic valve area measured by the continuous equation $(r=0.313 p<0.05)$, mean gradient pressure van $(r=0,412 p<0,01)$, max gradient pressure $(r=$ $0,411 \mathrm{p}<0,01)$. TAPSE, FAC, S'velocity, Tei were all strong corellate with left ventricular ejection fraction (EF) with correlation coefficient $(r=0,512 ; 0,658$; $0,372 ; 0,409 ; p<0,01)$. Conclusion: Right ventricular dysfunction is quite common in patients with aortic stenosis. Right ventricular function was correlated with peak systolic transaortic velocity (TAPSE), with aortic valve area index (FAC, S', Tissue Tei) and left ventricular systolic function.

Key word: aortic valve stenosis, echocardiography, right venticular function

\section{I. ĐẶT VẤN ĐỀ}

Trước đây các tác giả còn ít quan tâm đến chức năng thất phải ở các bệnh nhân mắc bệnh tim trái như bệnh van ĐMC, hở van hai lá. Gần đây với các tiến bộ của siêu âm tim trong đánh giá chức năng thất phải, đã có nhiều nghiên cứu về chức năng thất phải nói chung và chức năng thất phải ở BN hẹp van động mạch chủ khít. Các NC cho thây tỷ lệ rối loạn chức năng thất phải ở bệnh nhân hẹp van động mạch chủ khít dao động từ 10- 53\%. Rối loạn chức năng tâm thu thất phải làm tăng tỷ lệ tử vong chung trong vòng một năm là 78\% ở nhóm bệnh nhân thay van động mạch chủ qua da1. Tại Việt Nam đã có một vài nghiên cứu đánh giá chức nằng thất phải ở các bệnh nhân suy tim, sau nhôi máu cơ tim những chưa thây các nghiên cứu đánh giá chức năng thất phải trên các bệnh nhân hẹp van động mạch chủ. Vì vậy chúng tôi làm nghiên cứu này nhằm mục tiêu: Khảo sát tỷ lệ suy chức năng thất phài và tìm hiểu mối liên quan giữa chức năng thất phải với các thông số đánh giá mức độ hẹp van động mạch chủ, với chức năng thất trái ơ nhóm beenhjnhaan hẹp van động mạch chủ khít.

\section{II. ĐỐI TƯỢNG VÀ PHƯƠNG PHÁP NGHIÊN CỨU}

2.1 Đối tượng nghiên cứu. Đối tượng nghiên cứu của chúng tôi gồm 47 bệnh nhân đến khám và điều trị tại Viện tim mạch từ 08/2020 08/2021, được chẩn đoán xác định hẹp van động mạch chủ khít trên siêu âm tim (theo tiêu chuân của hội siêu âm tim hoa kì: vận tốc tối đa qua van > 4m/s, diện tích mở van động mạch chủ < $1 \mathrm{~cm} 2$, Chênh áp trung bình qua van $>40$ $\mathrm{mmHg}$ ). Loại trừ các bệnh nhân có các bệnh van tim khác ở mức độ nặng và những trường hợp có suy chức năng thất phải do nguyên nhân tăng áp phổi do bệnh tim bẩm sinh, tăng áp động mạch phổi tiên phát, nhồi máu cơ tim thất phải.

2.2 Phương pháp nghiên cứu. Nghiên cứu mô tả cắt ngang, chùm ca bệnh.

BN được khám lâm sàng, siêu âm tim, thu thập các thông số: Đặc điểm nhân trắc học (Tuổi, giới), Đặc điểm lâm sàng, các thông số siêu âm tim: mức độ hẹp van động mạch chủ dựa vào các thông sổ: vận tốc đa qua vạn động mạch chủ (Vmax), chênh áp trung bình qua van động mạch chủ (GradientTB), diện tích van động mạch chủ (đo qua phương trình liên tục), chỉ số 
diện tích van động mạch chủ. Kích thước và chức năng tâm thu thất trái: $\mathrm{FS}$, EF (simpson), $\mathrm{Dd}$, DS, LVMI. Thông số chức năng và kích thước thất phải: TAPSE, $F A C, S^{\prime}$, chỉ số Tei mo thất phải, $E / e^{\prime}$ vòng van ba lá, đường kính đáy thất phải (RVD1), đường kính giữa thất phải (RVD2), đường kính trục dọc thất phải (RVD3).

Xử Ií số liệu bằng phần mềm IBM SPSS statistic 20.

\section{KẾT QUẢ NGHIÊN CỨU} cứu

1.Đặc điểm của nhóm bệnh nhân nghiên

Bảng 1.1: Đặc điểm lâm sàng và cận lâm sàng của nhóm đối tượng nghiên cứu $(n=47)$

\begin{tabular}{|c|c|}
\hline Đặc điểm lâm sàng & $\begin{array}{c}\text { Kết quả }(X \pm S D \\
\text { hoăc } n, \%)\end{array}$ \\
\hline Tuối (năm) & $66,17 \pm 16,67$ \\
\hline Giới nam & $25(53,2)$ \\
\hline Tăng huyết áp & $24(51,1)$ \\
\hline Đái tháo đường & $4(8,5)$ \\
\hline Tai biến mach não & $2(4,3)$ \\
\hline Suy thân mạn & $2(4,3)$ \\
\hline Rối loạn lipid & $6(12,8)$ \\
\hline $\mathrm{BSA}(\mathrm{Kg} / \mathrm{m} 2)$ & $1,56 \pm 0,16$ \\
\hline Ngầt & $3(6,4)$ \\
\hline Đau ngực & $25(52,3)$ \\
\hline NYHA $>$ II & $42(89,4)$ \\
\hline Nhip xoang & $45(95,7)$ \\
\hline Tần số tim (nhịp/phút) & $78,63 \pm 15,01$ \\
\hline Huyết áp tâm thu $(\mathrm{mmHg})$ & $127,7 \pm 19,29$ \\
\hline Vmax qua van ĐMC $(\mathrm{m} / \mathrm{s})$ & $4,86 \pm 0,77$ \\
\hline $\begin{array}{l}\text { Chênh áp trung bình } \\
(\mathrm{mmHg})\end{array}$ & $59,14 \pm 19,49$ \\
\hline Diện tích mở van ĐMC (cm2) & $0,69 \pm 0,16$ \\
\hline Chỉ số Diên tích van (cm/m2) & $0,47 \pm 0,19$ \\
\hline EF simpson (\%) & $61,30 \pm 13,02$ \\
\hline LVMI $(\mathrm{g} / \mathrm{m} 2)$ & $189,2 \pm 60,34$ \\
\hline ALDMP $(\mathrm{mmHg})$ & $42,63 \pm 11,85$ \\
\hline
\end{tabular}

Nhận xét: Tỷ lệ bệnh nhân tăng huyết áp trong nghiên cứu chiếm tỷ lệ cao $51,1 \%$. Các bệnh nhân chủ yếu vào viện vì triệu chứng khó thở NYHA >II chiếm 89,4\%, trung bình diện tích mở van đo theo phương trình liên tục là $0,69 \pm$ $0,16 \mathrm{~cm}^{2}$.

150

50

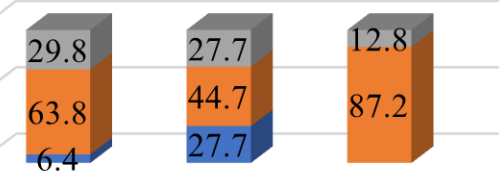

Van DMC Van hai lá Van ba lá

घ bình thường घHở nhẹ $\quad$ Hở vừa $\square$ Hở nặng

Biểu đồ 1.1: Mức độ hở van tim kèm theo của nhóm đối tượng nghiên cứu

Nhận xét: Các bệnh nhẩn chủ yếu có hở van tim ở mức độ nhẹ và̀ vừa. Không có bệnh nhân nào hở van tim ở mức độ nặng

Bảng 1.2: Tỷ lệ suy chức năng thât phải theo các thông số

\begin{tabular}{|c|c|}
\hline Thông số & $\begin{array}{l}\text { Suy chức năng thất } \\
\text { phải } N(\%)\end{array}$ \\
\hline \multicolumn{2}{|c|}{ Chức năng tâm thu } \\
\hline Tapse $<17 \mathrm{~mm}$ & 0 \\
\hline FAC $<35 \%$ & $2(4,3)$ \\
\hline $\mathrm{S}^{\prime}<9,5 \mathrm{~cm} / \mathrm{s}$ & $14(29,8)$ \\
\hline \multicolumn{2}{|c|}{ Suy CN tâm trương } \\
\hline$E / e^{\prime}$ Thất phải $>6$ & $20(41,9)$ \\
\hline \multicolumn{2}{|c|}{ Chức năng toàn bộ } \\
\hline Tei mô > 0,54 & $32(68,1)$ \\
\hline \multicolumn{2}{|c|}{ Giãn thất phải } \\
\hline RVD1 > 41mm & $5(10,6)$ \\
\hline RVD2 >35mm & $1(2,1)$ \\
\hline RVD3 >83mm & $5(10,6)$ \\
\hline
\end{tabular}

Nhận xét: Suy chức năng thất phải toàn bộ đánh giá qua chỉ số Tei mô chiếm tỳ lệ cao $68,1 \%$. Suy chức năng tâm thu thất phải đánh giá qua $S^{\prime}$ và $F A C$ lân lượt là $29,8 \%$ và $4,3 \%$. Không có bệnh nhân nào suy chức năng tâm thu thất phải khi đánh giá qua chỉ số Tapse. Suy chức năng tâm trương thất phải đánh bằng chỉ số $\mathrm{E} / \mathrm{e}^{\prime}$ chiếm $41,9 \%$

2 Mối liên quan giữa chức năng thất phải và các thông số khác.

Bảng 2.1 Mối liên quan giữa giới và các thông số đánh giá chức năng thất phải

\begin{tabular}{|c|c|c|c|}
\hline Thông số & Nam & Nữ & $\mathbf{P}$ \\
\hline Tapse $(\mathrm{mm})$ & $26,07 \pm 4,006$ & $26,217 \pm 3,40$ & 0,896 \\
\hline FAC $(\%)$ & $47,85 \pm 8,70$ & $49,708 \pm 6,71$ & 0,419 \\
\hline Tei mô & $0,800 \pm 0,3424$ & $0,747 \pm 0,302$ & 0,631 \\
\hline $\mathrm{S}^{\prime}(\mathrm{cm} / \mathrm{s})$ & $11,498 \pm 3,323$ & $11,10 \pm 3,73$ & 0,704 \\
\hline E/e'thất phải & $6,384 \pm 2,896$ & $4,871 \pm 2,362$ & 0,075 \\
\hline
\end{tabular}

Nhận xét: không thấy mối liên quan giữa tuối và các thông số đánh giá chức năng thất phải

Bảng 2.2 Mối liên quan giứa tuổi và các thống số đánh giá chức năng thất phái 


\begin{tabular}{|c|c|c|}
\hline Tương quan với tuối & $\mathbf{R}$ & $\mathbf{P}$ \\
\hline FAC $(\%)$ & 0,146 & 0,328 \\
\hline Tapse $(\mathrm{mm})$ & $-0,157$ & 0,291 \\
\hline Vận tốc sóng S' $(\mathrm{cm} / \mathrm{s})$ & $-0,044$ & 0,78 \\
\hline Tei mô & 0,097 & 0,517 \\
\hline E/e' thất phải & $-0,126$ & 0,699 \\
\hline
\end{tabular}

Nhận xét: không thấy sự khác biệt về các thông số đánh giá chức năng thất phải giữa 2 giới nam và nữ

Bảng 2.3: Liên quan chức năng thất phải với các thông số đánh giá mức độ hẹp van động mạch chủ

\begin{tabular}{|c|c|c|c|c|}
\hline Liên quan & Vqua van ĐMC & Svan & Svan/BSA & Gardient TB \\
\hline Tapse & $0,389(P<0,01)$ & $0,070(p>0,05)$ & $0,470(p>0,05)$ & $0,243(p>0,05)$ \\
\hline FAC & $0,188(p>0,05)$ & $0,285(p>0,05)$ & $0,364(p<0,05)$ & $0,193(p>0,05)$ \\
\hline$S^{\prime}$ & $0,069(p>0,05)$ & $0,293(p<0,05)$ & $0,302(p<0,05)$ & $-0,169(p>0,05)$ \\
\hline Tei mô & $0,057(p>0,05)$ & $-0,295(p<0,05)$ & $-0,297(p<0,05)$ & $0,227(p>0,05)$ \\
\hline RVD1 & $-0,181(p>0,05)$ & $0,323(p<0,05)$ & $0,265(p>0,05)$ & $-0,264(p>0,05)$ \\
\hline RVD3 & $-0,380(p<0,01)$ & $0,313(p<0,05)$ & $0,220(p>0,05)$ & $-0,412(p<0,01)$ \\
\hline RVD2 & $0,108(p>0,05)$ & $0,202(p>0,05)$ & $0,143(p>0,05)$ & $-0,009(p>0,05)$ \\
\hline
\end{tabular}

Nhận xét: Chỉ só Tapse có tương quan vữa với vận tốc qua van động mạch chủ( $r=0,389$ $\mathrm{p}<0,05)$, các chỉ số $\mathrm{FAC}, \mathrm{S}^{\prime}$, Tei mô đều cho thấy mối liên quan với chỉ số diện tích van động mạch chủ $(r=0,3640,302-0,297 p<0,05)$

Bảng 2.4: Môi tương quan giứa chức năng thất phải với các thông số đánh giá chức năng thất trái

\begin{tabular}{|c|c|c|c|c|c|}
\hline Liên quaan & Dd & Ds & FS & EF & ALDMP \\
\hline Tapse & $-0,27(p>0,05)$ & $-0,38(p<0,01)$ & $0,37(p<0,01)$ & $0,51(p<0,01)$ & $-0,30(p<0,05)$ \\
\hline FAC & $-0,43(p<0,01)$ & $-0,58(p<0,01)$ & $0,60(p<0,01)$ & $0,66(p<0,01)$ & $-0,34(p<0,05)$ \\
\hline$S^{\prime}$ & $-0,35(p<0,05)$ & $-0,40(p<0,01)$ & $0,34(p<0,05)$ & $0,41(p<0,01)$ & $-0,31(p<0,05)$ \\
\hline Tei mô & $0,21(p>0,05)$ & $0,25(p>0,05)$ & $-0,28(p>0,05)$ & $-0,37(p<0,05)$ & $0,03(p>0,05)$ \\
\hline RVD1 & $0,28(p>0,05)$ & $0,29(p<0,05)$ & $-0,13(p>0,05)$ & $-0,226(p>0,05)$ & $0,38(p<0,01)$ \\
\hline RVD2 & $0,215(p>0,05)$ & $0,142(p>0,05)$ & $0,03(p>0,05)$ & $-0,04(p>0,05)$ & $0,33(p<0,05)$ \\
\hline RVD3 & $0,39(p<0,01)$ & $0,42(p<0,01)$ & $-0,44(p<0,05)$ & $-0,5(p<0,01)$ & $0,39(p<0,01)$ \\
\hline
\end{tabular}

Nhân xét: Các chỉ số TAPSE, FAC, $\mathrm{S}^{\prime}$. Tei mô, RVD3 đều cho thấy mối liên quan mạnh với chức năng thất trái đo qua chỉ số $E F$ simpson với hệ số tương quan lần lượt là ( $r=0,510,660,41-0,37$ $\mathrm{p}<0,05)$

\section{BÀN LUẬN}

Ở bệnh nhân hẹp van động mạch chủ khít sự tiến triển của tái cấu trúc thất trái sẽ dẫn đến tăng áp lực thất trái cuối tâm trương đầy ngược trở laai nhĩ trái gây giãn nhĩ trái, tăng áp lực mao mạch phổi bít. Cuối cùng rối loạn chức năng thất phải xuất hiện như là hậu quả cuối cùng của tăng áp lực động mạch phổi. Bên cạnh đó thất phải và thất trái cũng có chung vách liên thất cùng bị hạn chế trong khoang màng ngoài tim, điều này gây ra tác động qua lại giữa hai buồng tim. 2,3

Trong nhóm beệnh nhân nghiên cứu tỷ lệ suy giảm chức năng tẩm toàn bộ thất phải xuất hiện nhiều nhất khi đánh giá qua thông số Tei mô $(>0,54)$ chiếm $68,1 \%$. Suy chức năng tâm thu thất phải khi đánh giá qua chỉ số $\mathrm{S}^{\prime}(<9,5 \mathrm{~cm} / \mathrm{s})$ và $\mathrm{FAC}(<35 \%)$ chiếm $29,8 \%$ và $4,3 \%$. Không có bệnh nhân nào được chẩn đoán suy chức năng tâm thu thất phải khi chẩn đoán dựa trên thống số Tapse $(<17 \mathrm{~mm})$. Tỷ lệ suy chức năng tâm trương thất phải khhi đánh giá bằng tỷ số $\mathrm{E} / \mathrm{e}^{\prime}(>6)$ là $41,9 \%$.

Chỉ số Tapse có tương quan vừa với vân tốc tối đa qua van động mạch chủ $(r=0,372 p=$ $0,012)$. Điều này cũng tương tự như trong nghiên cứu của Elena Galli $(r=0,24 p=0,001) 4$. Tuy nhiên khác với nghiên cứu của chúng tôi nghiên cứu này cho thấy có mối liên quan yếu giữa chỉ số này với chênh áp trung bình qua van động mạch chủ $(r=0,19 p=0,0060$ và diện tích van động mach chủ đo qua phương trình liên tuc $(r=0,17 p=0,001)$. Điều này có lẽ liên quan đến sự khác biệt về cõ̃ mẫu giữa hai nghiên cứu. Trong nghiển của chúng tôi cũng cho thấy mối liên quan vừa giữa các thông số $F A C, V s^{\prime}$, Tei mô với chỉ số diện tích van động mạch chủ theo BSA.

Nghiên cứu cũng cho thây các chỉ số TAPSE, FAC, S' đều có tương quan khá chặt chẽ với các thông số đánh giá đường kính và chức năng của thất trái đặc biệt là tỷ số EF với hệ tương quan 
lần lượt là 0,$512 ; 0,658 ; 0,409(p<0,01)$. Chỉ số Tei thất phải lại cho thấy mối tương quan nghịch biến với thông số này $(r=-0,372 p<0,05)$.

Nghiên cứu của Nguyễn Phương Trang trên nhóm bệnh nhân suy tim chức năng thất trái $\mathrm{EF}$ $<40 \%$ cũng cho thây mối tương quan mạnh giữa các chỉ số Tapse, FAC, $\mathrm{S}$ với thống số $\mathrm{EF}$ $(r=0,632 ; 0,710 ; 0,582 ; p<0,001) 5$. Điều này cũng tương tự như trong nghiên cứu của Nguyễn Bá Tâm trong nhóm bệnh nhân sau nhồi máu cơ tim thành trước cũng cho thấy mối liên quan giữa chỉ số Tapse và $E F(r=0,33, p<0,05) 6$. Nghiên cứu của Sarinya Puwanant và cộng sự năm 2009 đánh giá chức năng thất phải ở các bệnh nhân suy tim chức năng thất trái giảm và bảo tồn cũng cho thấy chỉ số Tapse, $\mathrm{FAC}, \mathrm{S}^{\prime}$ có tương quan tốt với chỉ số $E F$. FAC $(R=0,46 p<0,01)$ Tapse $(r=0,48 ; P<0,01) S^{\prime}(r=0,48 ; p=0,01) 7$

\section{KẾT LUÂN}

Suy chức năng thất phải khá thường gặp ở BN hẹp chủ khít. Chức năng thất phải có tương quan với vận tốc tối đa qua van động mạch chủ (TAPSE), với chỉ số diện tích van đông mạch chủ (FAC, S', Tei mô) và chức năng tâm thu thất trái.

\section{TÀI LIÊU THAM KHẢO}

1. Ren B, Spitzer E, Geleijnse ML, et al. Right ventricular systolic function in patients undergoing transcatheter aortic valve implantation: A systematic review and meta-analysis. Int J Cardiol. 2018;257:40-45. doi:10.1016/j.ijcard.2018.01.117

2. Right heart dysfunction in heart failure with preserved ejection fraction | European Heart Journal | Oxford Academic. Accessed August 11, 2021. https://academic.oup.com/ eurheartj/article/ $35 / 48 / 3452 / 472871$ ?login=true

3. Santamore WP, Dell'Italia LJ. Ventricular interdependence: Significant left ventricular contributions to right ventricular systolic function. Progress in Cardiovascular Diseases. 1998;40 (4):289-308. doi:10.1016/S0033-0620(98)80049-2

4. Galli $E$, Guirette $Y$, Feneon $D$, et al. Prevalence and prognostic value of right ventricular dysfunction in severe aortic stenosis. Eur Heart J Cardiovasc Imaging. 2015;16(5):531-538. doi:10,1093/ehjci/jeu290

5. Nguyễn Thu Trang NTBY. Khảo sát chức năng thất phải bằng siêu âm tim ở bệnh nhân suy tim có $\mathrm{EF}<40 \%$ so với nhóm suy tim EF $>40 \%$. Published online 2020. http://thuvien.hmu.edu.vn/ pages/cms/FullBookReader.aspx

6. Nguyễn Tá Tâm NTBY. Bước đâu đánh giá chưc năng thất phải bằng chỉ số Tapse trên siêu âm tim ở bệnh nhân nhồi máu cơ tim ST chênh lên sau can thiêp. Published online 2017. http://t huvien.hmu.edu.vn/pages/cms/FullBookReader.aspx

7. Puwanant S, Priester TC, Mookadam F, Bruce CJ, Redfield MM, Chandrasekaran K. Right ventricular function in patients with preserved and reduced ejection fraction heart failure. European Journal of Echocardiography. 2009;10(6):733-737. doi:10.1093/ejechocard/jep052

\title{
TẦN SUẤT SỬ DƯNG THỨC ĂN NHANH VÀ CÁC YẾU TỐ LIÊN QUAN CỦA HỌC SINH TRƯờnG TRUNG HỌC PHỔ THÔNG HÙNG VƯƠNG, THÀNH PHỐ HỒ CHÍ MINH
}

\author{
Trần Quốc Huy*, Nguyễn Ngọc Bích*, Đoàn Duy Tân*
}

\section{TÓM TẮT}

Đặt vấn đề: Thức ăn nhanh ngày nay phổ biến ở khắp nỡi trên thế giới và được người dân yêu thích sử dụng, trong đó có Viêtt Nam. Sử dụng thức ăn nhanh thường xuyên mất kiểm soát làm tăng nguy cơ mắc một số bệnh lý như thừa cân, béo phì, tăng huyết áp và các bệnh lý về đường tiêu hóa. Mục tiêu: Xác định tần suất sử dụng thức ăn nhanh vă các yếu tố liên quan của học sinh trường Trung hoc phổ thông (THPT) Hùng Vương năm 2021. Đối tượng và phương pháp nghiên cứu: Nghiên cứu mồ tả cắt ngang thực hiện trên 420 học sinh trường THPT Hùng

*Đại học Y Dược Thành phố Hồ Chí Minh

Chịu trách nhiệm chính: Đoàn Duy Tân

Email: doanduytaan@ump.edu.vn

Ngày nhận bài: 20.9.2021

Ngày phản biện khoa học: 2.11.2021

Ngày duyệt bài: 22.11.2021
Vương, quận 5, thành phố Hồ Chí Minh(TP.HCM) năm 2021. Kết quả: Tần suất sử dung thức ăn nhanh 1-3 lần/tháng của học sinh chiếm tỉ lệ cao nhất 43,3\%. Tỉ lê thừa cân ở hoc sinh THPT chiếm $15,7 \%$, tỉ lệ béo phì chiếm $4,3 \%$. Gà rán và khoai tây chiên là hai loai thức ăn nhanh sử dung phổ biến nhất với tỉ lệ lần lượt là $81,1 \%$ và $69,2 \%$. Thương hiệu thức ăn nhanh được sứ dụng nhiêuu nhất là KFC với $70,6 \%$. Lý do sử dụng thức ăn nhanh phổ biến nhất là hương vị chiếm $85 \%$. Nghiên cứu tìm thấy mối liên quan giữa tần suất sử dụng thức ăn nhanh với tần suất sử dụng bữa cơm gia đình $(p<0,001)$ và yếu tố $c h a / m e$ sử dụng thức ăn nhanh thường xuyên $(p<0,05)$. Kết luận: Để giảm tần suất sử dụng thức ăn nhanh của con cái, gia đình nên chủ động chuẩn bị và sử dụng bữa cớm gia đình cùng nhau, đồng thời phụ huynh nên han chế sử dụng thức ăn nhanh. béo phì.

Tư khóa: Thức ăn nhanh, dinh dưỡng, thừa cân 